Journal of Social Sciences 7 (4): 529-537, 2011

ISSN 1549-3652

(C) 2011 Science Publications

\title{
Attitudes of High School Students toward Physical Education and Their Sport Activity Preferences
}

\author{
Howard Z. Zeng, Michael Hipscher, and Raymond W. Leung \\ Department of Physical Education and Exercise Science \\ Brooklyn College of the City University of New York, USA
}

\begin{abstract}
Problem statement: Identifying and understanding correlates of school children's physical education activity participation are critical to promoting current and lifelong physical activity participation of children. Among other factors, children's attitudes are considered to be a key element influencing physical activity participation. Children who have more positive attitudes toward physical activity are reported to be more likely to participate in physical activity outside of school and demonstrate higher physical activity amounts than those with less positive attitudes. Fostering children's positive attitudes toward physical activity would be conducive to the promotion of current and lifelong physical activity participation of children. Aims at to examine high school students' attitudes toward Physical Education Activity (ATPEA) and their sports activities preferences. Approach: Participants were 1,317 students in grades 9-12th (603 boys and 714 girls) from five urban public school districts. The Physical Education Activity Attitude Scale (PEAAS) adapted version was employed for data collection. One-way ANOVA revealed that the five highest scores were Items 2, 16, 11,18 and 5 on the PEAAS. Results: The overall mean score $(70.160 \pm 3.948)$ indicated positive ATPEA for the participants. The independent group ANOVAs identified significant $(\mathrm{p}<0.01)$ differences in ATPEA scores with respect to participants' gender, ethnic group and Socio-Economic Status (SES). Girls scored higher than boys in Items 2, 13 and 15. Caucasian students scored higher than other four ethnic groups in Items 8 and 10. Students with middle SES scored higher than students with low and high SES in Item 2. Conclusion: The current ATPEA status of the participants appears to be positive. There are some crucial factors that structure the participants' ATPEA. These factors are related to students' perception, benefit, care and value about physical education programs and sports activities.
\end{abstract}

Key words: Perception, value of program, team sport, aerobic exercise, Physical Education (PE), sports activities, activity preferences, theoretical framework, Attitudes Toward Physical Education Activity (ATPEA)

\section{INTRODUCTION}

Researchers in the field of Physical Education (PE) indicated that identifying and understanding the factors that are associated with children's physical activity participation are critical to the promotion of current and lifelong physical activity participation (Chung and Phillips, 2002; Ding et al., 2006; Sallis et al., 2000) Among many factors, the children's attitude is considered to be a key factor that influences physical activity participation (Chung, M. and D.A. Phillips, 2002; Ding et al., 2006; Hagger et al., 1995; Solmon, 2003).

Rikard and Banville (2006) stated that attitudes are born from beliefs that one's has about him or herself and things. Attitudes shape ones' behaviors in many ways and determine ones' involvement in him or her daily activities (Rikard and Banville, 2006). Developed a theoretical framework for a rational action, their framework further explained attitudes flow come from beliefs and yield intentions and actions. While intentions are a function of two basic determinants: (a) one's personal attitude toward a behavior and (b) one's attitude toward others (i.e., peers, teacher/leader and parents). The first determinant is the individual's positive or negative evaluations for performing the behavior; It just as Silverman and Subramaniam (1999) indicated: generally, with positive beliefs one will have a favorable attitude toward the object of the beliefs; otherwise one will possess an unfavorable attitude toward the object of the beliefs ${ }^{[28]}$. The second determinant is the person's perception of social

Corresponding Author: Howard Z. Zeng, Department of Physical Education and Exercise Science,

Brooklyn College of the City University of New York, United States 
pressure to perform or not perform the behavior based on the evaluation of others. Therefore, an attitudinal consideration and a normative consideration are formed that exert different degrees of power toward influencing one's behaviors for more positive or negative responses (Rikard and Banville, 2006).

Strand and Scantling (1994) pointed out that people express their beliefs and attitudes daily through behaviors and language. In PE, obtaining students' insight into their beliefs is a critical source for understanding their attitudes and their interests and involvement toward their PE program (Strand and Scantling, 1994).

Researchers indicated that children who have more positive attitudes toward physical activity are reported to be more likely to participate in physical activity outside of school (Chung and Phillips, 2002; Ding et al., 2006; McKenzie, 2003; Portman, 2003) and demonstrate higher physical activity levels (Hagger et al., 19985) than those with less positive attitudes. According to a review of literature on children's Attitudes toward Physical Education/Activity (ATPEA) by Solmon (2003), children's characteristics and contextual factors are two major factors that are related to children's attitudes. Children's characteristics refer to children's age, gender and sports skill. Contextual factors include the quality of physical education programs and the accessibility of after school physical activities.

With regard to children's characteristics, elementary children are found to have more positive attitudes than secondary school children (Lee, 2004; Martin, 2000; Solmon and Carter, 1995; Xiang et al., 2004) and children's attitudes become less positive as they progress through their schooling (Biddle and Mutrie, 2008; Lee, 2004; Prochaska et al., 2003; Xiang et al., 2004). It is also found that elementary school children express very favorable attitudes toward health, fitness, enjoyment and social interaction benefits of physical activity, but do not enjoy physical activities involving hard practice and risk-taking movements (Patterson and Faucette, 1990). Lee (2004) found that the younger children possess more positive attitudes toward physical activity and show more interests toward all kinds of physical activities. However, the reliability of younger children responding to questions might need to be carefully considered due to their lower self-evaluation ability (Lee, 2004).

With regard to contextual factors, the quality of physical education programs has been reported to be a strong factor influencing children's ATPEA, Subramaniam and Silverman (2002) indicated that school children's positive attitudes are likely to be associated with enjoyment, perceived usefulness of the curriculum and a sense of belongingness [33]. Curriculum with situational interests, such as those requiring students to analyze and design offensive and defensive strategies, may foster students' interests in physical activity (Chen and Darst, 2001). A learning environment that promotes personal meaning is considered to be important to the development of positive attitudes (Rink, 2006). Children are also likely to become more positive toward physical activity if they are in a learning environment that makes them comfortable and confident (Hagger et al., 2003).

Carlson (1995) indicated that students would lose interest in physical activity if the subject matter lacks challenges or the instructors repeat the same class activities without bringing fun to the children ${ }^{[4]}$. Siedentop (2004) also argued that a multi-activity curriculum with a series of short-term units would negatively influence the attitudes of students toward physical education. In contrast found that it is difficult for students to maintain interests in traditional team sports than in individual sports or activities. Additionally, Tannehill et al. (1994) found that, if physical education in school curricula becomes a marginal status, it would have a negative impact on students' attitudes (Subramaniam and Silverman, 2007).

Gender difference is another factor that has been addressed in children's ATPEA research. In the studies comparing the differences of attitudes toward physical education between girls and boys by Birtwistle and Brodie (1991), Folsom-Meek (1992) and Hick et al. (2001), girls were found more favorable ATPEA emphasizing aesthetics, whereas boys were found more positive ATPEA in challenging and risk-taking activities (Folsom-Meek, 1992; Papaioannou, 1994). Specifically, Greenwood and Stillwell, (2001) reported that boys demonstrated strong interests in archery, bowling, flag football and wrestling, whereas girls preferred gymnastics, softball and volleyball (Greenwood and Stillwell, 2001). Furthermore, boys were reported to have more positive attitudes than girls toward physical activities bringing them risk-taking experiences, whereas girls were more positive than boys in physical activities with beautiful and graceful movements (Colley et al., 1994; Hick et al., 2001; Parkhurst, 2000). Subramanian and Silverman (2002), however, did not find gender difference in attitudes between boys and girls toward physical education (Subramaniam and Silverman, 2007). 
With regard to children's sports/activities preferences, Greenwood and Stillwell (2001) found that children had strong interests in basketball, bicycling, roller-skating, soccer, swimming and volleyball and had little interests in folk or square dancing, badminton, field hockey and floor hockey (Greenwood and Stillwell, 2001). Parkhurst, (2000) conducted a study to compare the attitudes toward physical activity and physical activity levels of sixth grade children in different ethnic groups. Parkhurst found that African American boys possessed more positive attitudes in the ascetic sub domain than African American girls. Regardless of ethnicity, boys possessed higher physical activity levels than girls (Parkhurst, 2000). Concerning Socio-Economic Status (SES), limited research has been conducted to examine how SES affects children's attitudes toward physical activity and participation in sports and physical activities.

Since 1990, there has been an increase in the body of knowledge in children's ATPEA. The increased interest in this topic might be attributed to the influence of attitudes toward further participation in physical activities after school (e.g., studies by (Papaioannou, 1994; Strand and Scantling, 1994; Subramaniam and Silverman, 2002; Tannehill et al., 1994) and further participation in physical activities out of school that related to achievements in students' sport competition (Graham et al., 2007; Lee, 2004; Strand and Scantling, 1994; Subramaniam and Silverman, 2002). Researchers also reported that students tend to participate in physical activities continually when they perceive the activities to be fun and enjoyable (Silverman and Subramanian, 1999). As most of the previous studies were conducted at the elementary and middle school levels, examining the ATPEA of high school students is important.

New York City (NYC) is the most populous and diverse city in the United States. The City is the center of international finance, politics, entertainment and culture. The City includes the largest population of immigrants from over 180 countries. Moreover, the City contains the largest public school system in the nation, with over 1 million students taught throughout 1,200 separate schools. To the knowledge of the investigators, no studies have been conducted to examine students' ATPEA and sports/activities preferences in this City where both the educational system and the students' population possess the most diverse characteristics on earth. Hence, the purpose of this study was to examine the current status of ATPEA and sports/activities preferences of the high school students in the City of New York.

\section{MATERIAL AND METHODS}

Participants: Ten public high schools were recruited voluntarily from five school districts of New York City (two schools from each school distract of the NYC). A total of 1,317 participants in grades 9-12 (603 boys and 714 girls, aged $16.79 \pm 1.14 \mathrm{yr}$ ) returned the informed consent signed by their parent and voluntarily completed the questionnaire. Among the participants, $54.21 \%$ were females, $72.51 \%$ claimed they preferred co-ed class format and $74.26 \%$ claimed they came from middle-income family which is families with annual incomes between about $\$ 40,000$ and $\$ 65,000$. The percentages of participants came from different ethnic groups reflected the diverse characteristics of this urban city with $10.86 \%$ Caucasian, $21.56 \%$ Africa American, 42.82\% Hispanic, $22.32 \%$ Asian and others $2.44 \%$.

Physical education characteristics of the selected school districts: The characteristics of the physical education lessons provided by the selected school districts were as follows: (a) Each high school provided physical education lessons on the content knowledge of basic motor and manipulative skills, cardiorespiratory endurance, flexibility, muscular strength, muscular endurance and body composition; (b) Students were required to participate in physical activities that develop physical fitness skills, demonstrate fundamental motor, non-locomotor and manipulative skills, understand the effects of activity on the body and the risks associated with inactivity, understand the relationship between physical activity and individual well being; (c) Students learned the necessary knowledge and skills to establish and maintain physical fitness, to participate in physical activity and to maintain personal health. The students had one physical education lesson per day, five days per week.

Questionnaires: Two questionnaires were administered to the participants. The first questionnaire was the Physical Education Activity Attitude Scale (PEAAS) originally developed. This was a study and pencil selfreport questionnaire with a 5-point Likert-type scale with responses ranging from 1 (Strongly Agree) to 5 (Strongly Disagree) summed across 20 items, resulting in a range of scores from 20-100. A score of 20 indicated the most negative attitude, 21-40 indicated a negative attitude, 41-60 indicated a neutral attitude, 61-80 indicated a positive attitude and 81-100 indicated a highly positive attitude (Appendix A). The second questionnaire was the Sports/Activities Preference Questionnaire (see Appendix B) developed by the Principal Investigator (PI). This questionnaire 
contained eight questions that asked the participants to self-report the activities they preferred and their demographic information. This questionnaire had a Cronbach Alpha reliability coefficient of.92, an intraclass correlation coefficient of 0.90 and a scale validity coefficient of 0.93 .

Data collection procedures: After the schools were selected, permission to conduct the current study was granted by the administrators of the schools. In the letter to the school administrators, the purposes, procedures and potential outcomes of the study were described. Students were then asked if they would be willing to participate in the study. The volunteer students signed the inform consent forms. The questionnaires were administered by their instructors in physical education class settings and the students completed the questionnaires. After the questionnaires were collected, the investigators checked the completion of each questionnaire and the incomplete questionnaires were eliminated. In the current study, the completion rate was $87.8 \% \quad(1,317$ out of 1,500 questionnaires). Additionally, unofficial interviews with the program directors of the high schools were carried out during this study and the interview questions focused on their facilities, equipment, traditional sports, physical education and activities curriculum and state and school district requirements.

Statistics analyses: Descriptive statistics were computed in regard to the high school students' ATPEA. A one-way Analysis Of Variance (ANOVA) was utilized to determine the current status of the ATPEA for the participants. Furthermore, independent group ANOVAs that determined the differences in ATPEA scores with respect to participants' gender, ethnic groups and SES were also conducted.

\section{RESULTS}

The aim of this study was to examine the ATPEA and sports/activities preferences of the high school students in the public schools from the five boroughs of New York City. The descriptive statistics with respect to the ATPEA scores for the participants from the PEAAS are presented in Table 1.

The highest score $(\mathrm{M}=4.004 \pm 0.988)$ was Item 2 , in which the participants believed that "Physical education is not only beneficial to those who are already in good body conditioning". In other words, the participants believed that physical education should be beneficial to anyone who regularly participates in it. The second highest score was Item $16(\mathrm{M}=$ $4.002 \pm 0.911)$, in which the participants believed that "During high school years, anybody who is serious about physical education is not foolish". The third highest score was Item $11(\mathrm{M}=3.961 \pm 0.829)$, in which the participants actually believed that "Physical exercise is the best way to obtain a youthful looking and agile body."

The top five high scores, in rank order, answered by the participants were Items 2, 16, 11, 18 and 5 (Table 1).

The fourth highest score was Item 18 ( $\mathrm{M}=$ $3.942 \pm 1.038)$, in which the participants did not believe that "High school would be better without physical education/activities classes." In other words, the participants believed that without physical education, high school would not be possible as it is supposed to be. The fifth highest score was Item 5 (M = $3.887 \pm 0.903)$, in which the participants believed that "Physical exercise provides an important relief from the stress of one's daily life." In other words, the high school students felt that physical exercises bring them fun and relaxation and are their essential daily activities. Moreover, the overall mean score for the 20 items was $70.160 \pm 3.948$ indicating that the participants in the current study certainly possessed positive ATPEA.

Results of the participants' sports/activities preference are presented in Table 2. Nearly sixty-two percent of the students reported that they preferred playing team sports; $22.85 \%$ of the students reported that they liked to play individual sports; and $15.19 \%$ of the students were in favor of playing dual game sports. Among the five activities, aerobic exercise (35.91\%) was the most favorite activity and weight lifting $(23.01 \%)$ was ranked second. Other activities, such as dance (19.50\%), outdoor adventure (11.92\%) and martial arts $(8.12 \%)$, were ranked right after.

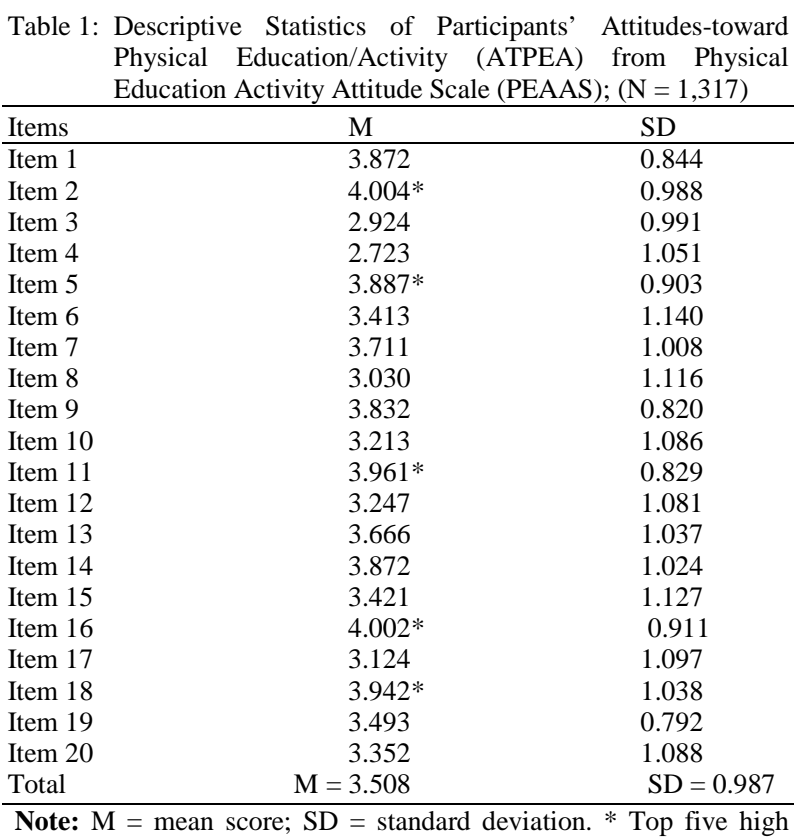
score items 
Table 2: Participants' sports/activities preferences survey: the results summary $(\mathrm{N}=1.317)$

\begin{tabular}{lll}
\hline Factors & $\mathrm{n}$ & $(\%)$ \\
\hline Sports preferences & 816 & \\
Team sports & 301 & 61.96 \\
Individual sports & 200 & 22.85 \\
Dual game sports & & 15.19 \\
Activities preferences & 473 & \\
Aerobic exercise & 303 & 35.91 \\
Weight lifting & 277 & 23.01 \\
Dance & 157 & 19.50 \\
Outdoor adventure & 107 & 11.92 \\
Martial arts & & 8.12 \\
\hline
\end{tabular}

Table 3: Comparisons to determine the differences in attitudes toward physical education/activities scores for participants with respect to gender, ethnic groups and social economic status $(\mathrm{n}=1.317)$

\begin{tabular}{|c|c|c|c|c|}
\hline Factors & $\mathrm{n}$ & M & SD & $\mathrm{p}$ \\
\hline \multicolumn{5}{|l|}{ Gender } \\
\hline Item 2 & & & & \multirow[t]{3}{*}{0.003} \\
\hline Male & 603 & 3.811 & 0.897 & \\
\hline Female & 714 & 3.923 & 0.793 & \\
\hline Item & & & & \multirow[t]{3}{*}{0.011} \\
\hline Male & 603 & 3.587 & 1.099 & \\
\hline Female & 714 & 3.732 & 0.976 & \\
\hline Item 15 & & & & \multirow[t]{3}{*}{0.006} \\
\hline Male & 603 & 3.328 & 1.180 & \\
\hline Female & 714 & 3.498 & 1.075 & \\
\hline \multicolumn{5}{|l|}{ Ethnic groups } \\
\hline Item 8 & & & & \multirow[t]{6}{*}{0.000} \\
\hline Caucasian & 143 & 3.343 & 1.126 & \\
\hline African A & 284 & 2.863 & 1.089 & \\
\hline Hispanic & 564 & 2.969 & 1.110 & \\
\hline Asian & 294 & 3.136 & 1.109 & \\
\hline Others & 32 & 3.113 & 1.089 & \\
\hline Item 10 & & & & \multirow[t]{6}{*}{0.007} \\
\hline Caucasian & 143 & 3.427 & 1.045 & \\
\hline African A & 284 & 3.074 & 1.069 & \\
\hline Hispanic & 564 & 3.168 & 1.090 & \\
\hline Asian & 294 & 3.340 & 1.080 & \\
\hline Others & 32 & 3.056 & 1.125 & \\
\hline Item 18 & & & & \multirow[t]{6}{*}{0.005} \\
\hline Caucasian & 143 & 4.056 & 0.940 & \\
\hline African A & 284 & 3.838 & 1.051 & \\
\hline Hispanic & 564 & 3.878 & 1.080 & \\
\hline Asian & 294 & 4.092 & 0.968 & \\
\hline Others & 32 & 3.930 & 1.162 & \\
\hline \multicolumn{4}{|c|}{ Social economic status } & \multirow{5}{*}{0.003} \\
\hline Item 19 & & & & \\
\hline High & 159 & 3.214 & 0.874 & \\
\hline Middle & 978 & 3.441 & 0.780 & \\
\hline Low & 180 & 3.383 & 0.757 & \\
\hline
\end{tabular}

Note: Only the top three significant $(\mathrm{p}<0.05)$ findings were presented; $\mathrm{M}=$ mean, $\mathrm{SD}=$ standard deviation. African $\mathrm{A}=$ African American

Furthermore, the comparisons for determining the differences with respect to gender, ethnic groups and SES were computed using independent group ANOVAs (Table 3).

Gender differences showed that for item 2, female students $(\mathrm{M}=3.923 \pm 0.793 ; \mathrm{DF}=1, \mathrm{~F}=8.615)$ scored significantly $(\mathrm{p}=0.003)$ higher than those of male students $(M=3.811 \pm 0.897)$. For item 13 , the female students $(\mathrm{M}=3.732 \pm 0.976 ; \mathrm{DF}=1, \mathrm{~F}=6.457)$ scored significantly $(\mathrm{p}=0.011)$ higher than those of males $(\mathrm{M}$ $=3.587 \pm 1.099)$. For item 15 , the female students $(\mathrm{M}=$ 3.498__1.075; $\mathrm{DF}=1, \mathrm{~F}=7.49$ ) scored significantly ( $\mathrm{p}$ $=.006)$ higher than those of male students $(\mathrm{M}=$ $3.328 \pm 1.180$ ). Concerning the differences among the ethnic groups, for item 8, the Caucasian group $(\mathrm{M}=$ $3.343 \pm 1.126 ; \mathrm{DF}=4, \mathrm{~F}=4.720)$ scored significantly ( $\mathrm{p}$ $=.000)$ higher than other three groups $(\mathrm{M}=$ $3.427 \pm 1.045)$. For item 10, the Caucasian group $(\mathrm{M}=$ $3.427 \pm 1.045 ; \mathrm{DF}=4, \mathrm{~F}=3.218)$ scored significantly ( $\mathrm{p}$ $=0.007)$ higher than other three groups $(\mathrm{M}=$ $3.427 \pm 1.045)$. For item18, the Asian children ( $\mathrm{M}=$ 4.092 $\pm 0.968 ; \mathrm{DF}=4, \mathrm{~F}=3.413$ ) and the Caucasian children $(\mathrm{M}=4.056 \pm 0.940)$ scored similarly whereas the Hispanic children $(\mathrm{M}=3.878 \pm 0.1 .080)$ and the Africa. American children $(\mathrm{M}=3.838 \pm 1.051)$ also scored very similar. In regard to the SES factor, only one significant $(\mathrm{p}=0.003)$ difference was found, that was Item 19, in which children from middle income family scored $\mathrm{M}=3.441 \pm 0.780, \mathrm{DF}=2, \mathrm{~F}=5.733$; children from low income family scored $\mathrm{M}=$ $3.383 \pm 0.757$; and children from high income family scored $\mathrm{M}=3.214 \pm 0.874$.

\section{DISCUSSION}

The present study examined the current status of the participants' attitude toward ATPEA and their sport/activities preference. At the same time, this study also addressed the differences on ATPEA of the high school students with regard to their gender, ethnicity and SES. Generally speaking, the findings of this study indicated that the overall mean score over the 20 items

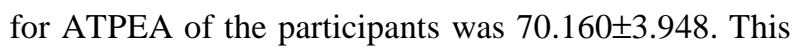
result indicated that the current ATPEA status of the participants is positive. The top five highest scores were Item 2 which stated that "Physical education is not only beneficial to those who are already in good body conditioning"; Item 16 which stated that "During high school years, anybody who is serious about physical education is not foolish"; Item 18 which stated that "High school would be better without physical education/activities classes"; Item 11 which stated that "Physical exercise is the best way to obtain a youthful looking and agile body"; and Item 5 which stated that "Physical exercise provides an important relief from the stress of one's daily life". We believe these factors are important in structuring the ATPEA of the participants. 
Concerning the sport preference of the participants, with a wide range of selection from the physical education curriculum (team sports: football, baseball, basketball, volleyball and soccer; individual sports: Swimming, Track and Field; and dual game sports: tennis, badminton and table tennis), team sports are the participants' first choice, individual sports second and dual game sport third (Table 2). These findings might be attributed to the influence of the following three factors: (a) the status of facilities and equipment of the schools; (b) the school's tradition and teachers' skill expertise; and (c) the majority students' preference. According to the unofficial interviews with the program directors of these high schools, all these schools have excellent facilities and equipments for team sports, fair facilities and equipment for individual sports, but fairly good facilities and equipment for dual game sports. Moreover, these program directors claimed that they have at least one team sport as their school's traditional sport.

Among the five optional physical activities, the order of the participants' favor was: aerobic exercise, dance, weight lifting, outdoor adventure and martial arts. According to the unofficial interviews with the program directors of these high schools, the activities preferences of these high school students might be attributed to the school district requirements, the traditional activities of the school, the influence of physical education teachers' expertise and preference, the environment of physical education classes and the ethnic and cultural background. For example, Caucasian and Africa American children like and are good at team sports, Hispanic children like and are good at dancing and Asian children prefer to play individual sports and martial arts. The present result was related to the finding of Hagger et al. (2002) suggesting that students are likely to become more positive toward physical activity if they are in a learning environment that makes them comfortable and confident (Hagger et al., 1995). According to the program directors of these high schools, since 2005, the school districts in New York City have provided a wide range of options in physical activities classes for students to choose from or take part and the learning environments in those high schools are also comfortable and make their students feel comfortable and confident.

With regard to the gender differences between boys and girls, the current study found significant gender differences in the ATPEA scores in Items 2, 13 and 15. As the study hypothesized that, gender would have significant differences on participants' ATPEA. The present results showed that the hypotheses were true. The findings of this study were slightly inconsistent with the previous studies reporting that boys had more positive ATPEA than girls (Koca and Demirhan, 2004; Parkhurst, 2000; Subramaniam and Silverman, 2007). The current findings were consistent with the findings of the following studies (Colley et al., 1994; Hagger et al., 1995; Parkhurst, 2000) indicating that, as physical activities focused on aesthetics with beautiful and graceful movements (e.g., dance, gymnastics and yoga), girls showed more positive ATPEA than boys.

On the other hand, in the studies of the children's attitudes toward physical activity, boys were found to have more positive attitudes toward physical activities that were challenging and had elements of risk (Folsom-Meek, 1992; Smoll and Schutz, 1980; Subramaniam and Silverman, 2007). In this aspect, the current study also found that boys were more favor of the sports and activities of soccer, basketball, weight lifting, outdoor adventure and martial arts and had more positive ATPEA than girls. It is worth pointing out that, the finding of "the female high school students are serious about their physical education classes and regard physical education classes as important as other academic classes" (see Items 13 and 15 and the Results section for detail) was new to the ATPEA study and was different from other previous studies.

Concerning the ethnic factor, significant differences in the ATPEA scores among the five ethnic groups were found in Items 8, 10 and 18. Caucasian children scored higher in Item 8 and Item 10 than the other four ethnic groups and they scored second high in Item 18 among the five groups. These findings demonstrated that Caucasian children had better understanding of the importance of physical education and exercise in their life. Asian children scored the highest in Item 18, scored the second in Item 8 and scored the third in Item 10 among the five groups, thus illustrating that Asian children' ATPEA were in the second position that was right after the Caucasian children. The mean ATPEA score from Items 8, 10 and 18 for Hispanic and Africa American groups were in the fourth and fifth position among the five groups. These data might be due to the fact that this population represented the largest sample size in this survey with a very large standard deviation, thus resulting in their mean ATPEA score in the fourth and fifth position because some children scored very high but other children scored low. This finding might provide the future direction to foster urban high school students' ATPEA for our educators.

Lastly, concerning how the SES affected participants' ATPEA. The only significant difference was Item 19, stating that "There is a scientific basis for the value of physical education/activity." In Item 19, the children from middle-income family scored higher than those children from low and high-income families. 
The reason for the difference was unknown. Additionally, the current study also examined the preferences of students in co-ed or single-sex physical education class formats. Results showed that nearly $75 \%$ of the students claimed they preferred a co-ed class format whereas about $25 \%$ of the students claimed they preferred a single-sex class format. A reason for this finding might be related to the fact that the U.S. public educational system did not promote the singlesex physical education class format. Currently, New York City public schools do not have the single-sex physical education class format and the participants do not know the advantages and disadvantages of the single-sex physical education class format.

\section{CONCLUSION}

In summary, the current ATPEA status of the participants appears to be positive. The crucial factors that structure the participants' ATPEA are likely be: (a) 'benefits' (e.g., Item 1, 3, 5 and 11); (b) 'serious degree' (e.g., Item 6, 10, 15 and 16); (c) 'perception' (e.g., Item 2, 4, 8 and 14); and (d) 'value' (e.g., Item 9, 12, 18 and 19) about their physical education classes and physical exercises. The participants' sport preference is: team sports, individual sports and dual game sports. The participants' favorite activities are: aerobic exercise, dance, weight lifting, outdoor adventure and martial arts.

In general, both male and female participants show positive and similar ATPEA. This finding is consistent with most previous studies. In specific, the female participants in the current study show more positive attitudes about their physical education classes than those of the male participants and regard physical education classes as important as other academic classes. Concerning the ethnic factor, different ethnic groups show different favoritism on certain factors. The reasons might be related to the cultural background, the environment of PE classes and the influence of PE teachers. Regarding the co-ed versus single-sex PE class formats, most participants indicate that they are in favor of the co-ed class format.

Finally, according to the findings of this investigation and the unofficial interview with the program directors of these high schools, we would like to offer the following recommendations to improve PE experiences and promote positive ATPEA in the urban high school students: (1) Increase the participation of PE teachers during their classes the physical activities (role model and leading by example). (2) Increase the number of students engaged in motor activities within class time the national goals for school physical education programs emphasize that $50 \%$ or more of class time should be spent with students being physically active (U.S. Department of Health and Human Services, 2000). (3) Multiple teaching strategies are recommended to be applied to meet the needs of diverse learners (Zeng et al., 2010). (4) To offering a wide variety of sports and activities for whom to choose. (5) Students' cultural background and gender characteristics must be taken into consideration when planning for their lessons or programs.

Briefly speaking, the solutions are lying in a multiple dimensional relationship between school environment, economic realities, cultural factors and educational policy. Further research is necessary to discover it. The bottom line is: if we can change school children's attitudes toward PE and have daily physical activities become a part of their life, we will able to reduce the risk the hazards of a sedentary lifestyle when they growing up.

\section{ACKNOWLEDGEMENTS}

This research study was supported by a research grant from the Research Foundation of the City University of New York. USA. The grantee was Dr. Howard Z. Zeng-the Principal investigator of this research project.

\section{REFERENCES}

Biddle, S.J.H. and N. Mutrie, 2008. Psychology of Physical Activity: Determinants, Well-Being and Interventions. 2Edn., Routledge, New York, pp: 428. ISBN: 041536664X

Birtwistle, G.E. and D.A. Brodie, 1991. Children's attitudes towards activity and perceptions of physical education. Health Educ. Res., 6: 465-478. doi: $10.1093 /$ her/6.4.465

Carlson, T.B., 1995. We hate gym: Student alienation from physical education. J. Teach. Phys. Educ., 4: 467-477.

Chen, A. and P.W. Darst, 2001. Situational interest in physical education: A function of learning task design. Res. Quar. Exerc. Sport, 72: 150-164.

Chung, M. and D.A. Phillips, 2002. The relationship between attitude toward physical education and leisure-time exercise in high school students. Phys. Educ., 59: 126-138.

Colley, A., C. Comber and D.J. Hargreaves, 1994. Gender effects in school subject preferences: A research note. Educ. Studies, 20: 13-18. DOI: 10.1080/0305569940200102

Ding, S., P.M. Wright and W. Li, 2006. Exploring the relationship between a caring climate and student attitudes toward physical education in an urban high school. Res. Quar. Exerc. Sport, Suppl. 
Folsom-Meek, S.L., 1992. A comparison of upper elementary school children's attitudes toward physical activity. Educ. Res. Inf. Center.

Graham, G., S.A. Holt-Hale and M. Parker, 2006. Children Moving: A Reflective Approach to Teaching Physical Education. 7th Edn., McGrawHill, New York, ISBN: 0071108432, pp: 985.

Greenwood, M. and J. Stillwell, 2001. Activity preferences of middle school physical education students. Phys. Educ., 58: 26-29.

Hagger, M., L. Cale and L. Almond, 1997. The importance of children's attitudes towards physical activity. Eur. Phys. Educ. Rev., 3: 144-164. DOI: 10.1177/1356336X9700300205

Hagger, M.S., N.L. Chatzisarantis and J.H. Biddle, 2002. A meta-analytic review of the theories of reasoned action and planned behavior in physical activity: Predictive validity and the contribution of additional variable. J. Sport Exerc. Psychol., 24: 3-32.

Hick, M.K., M.S. Wiggins, R.W. Crist and F.M. Moode, 2001. Sex differences in grade three students' attitudes toward physical activity. Perceptual Motor Skills, 93: 97-102. DOI: 10.2466/PMS.93.5.97-102

Koca, C. and G. Demirhan, 2004. An examination of high school students' attitudes toward physical education with regard to gender and sport participation. Perceptual Motor Skills, 98: 754-758. DOI: $10.2466 / \mathrm{pms} .98 .3 .754-758$

Lee, A.M., 2004. Promoting lifelong physical activity through quality physical education. J. Phys. Educ. Rec. Dance, 75: 21-26.

Martin, L.T., 2000. Perceptions of high, average, and low performance second graders about physical education and physical education teachers. Phys. Educ., 59: 204-219.

McKenzie, T.L., 2003. Health-related Physical Education: Physical, Activity Fitness and Wellness. In: Student Learning in Physical Education: Applying Research to Enhance Instruction, Silverman, S.J. and C.D. Ennis, (Eds.). Human Kinetics, Champaign, pp: 207-226.

Papaioannou, A., 1994. Development of a questionnaire to measure achievement orientations in physical education. Res. Quar. Exerc. Sport, 65: 11-20.

Parkhurst, D.L., 2000. Comparison of attitudes toward physical activity and physical activity levels of sixth grade boys and girls of various ethnic origins. Thesis/dissertation, Manuscript, University of Oregon.

Patterson, P., and N. Faucette, 1990. Attitudes toward physical activity of fourth and fifth grade boys and girls. Res. Quar. Exerc. Sport, 61: 415-418.
Portman, P.A., 2003. Are physical education classes encouraging students to be physically active? Experience of ninth graders in their last semester of required physical education. Phys. Educ., 60: 150-160.

Prochaska, J.J., J.F. Sallis, D.J. Slymen and T.L. McKenzie, 2003. A longitudinal study of children's enjoyment of physical education. Pediat. Exerc. Sci., 15: 170-178.

Rikard, G.L. and D. Banville, 2006. High school student attitudes about physical education. Sport Educ. Soc., 11: 385-400.

Rink, J., 2006. Teaching Physical Education for Learning. 6th Edn., McGraw-Hill, New York, ISBN: 0073376523, pp: 416.

Sallis, J.F., J.J. Prochaska and W.C. Taylor, 2000. A review of correlates of physical activity of children and adolescents. Med. Sci. Sports Exerc., 32: 963-975.

Siedentop, D., 2008. Introduction to Physical Education, Fitness and Sport. 7th Edn., McGrawHill, Boston, ISBN: 0073376515, pp: 448.

Silverman, S. and P.R. Subramaniam, 1999. Student attitude toward physical education and physical activity: A review of measurement issues and outcomes. J. Teach. Phys. Educ., 19: 97-125.

Smoll, F.L. and R.W. Schutz, 1980. Children's attitudes toward physical activity: A longitudinal study. J. Sport Psychol., 2: 137-147.

Solmon, M.A. and J.A. Carter, 1995. Kindergarten and first-grade students' perceptions of physical education in one teacher's classes. Element. School J., 95: 355-365. DOi: 10.1086/461808

Solmon, M.A., 2003. Student Issues in Physical Education: Attitudes, Cognition and Motivation. In: Student Learning in Physical Education: Applying Research to Enhance Instruction, Silverman, S.J. and C.D. Ennis, (Eds.). Human Kinetics, Champaign, ISBN : 073604275X, pp: 147-162.

Strand, B. and E. Scantling, 1994. An analysis of secondary student preferences towards physical education. Phys. Educ., 51: 119-129.

Subramanian, P.R. and S. Silverman, 2000. Validation of scores from and instrument assessing student attitude toward physical education. Measurement Phys. Educ. Exerc. Sci., 4: 29-40. DOI: 10.1207/S15327841Mpee0401_4

Subramanian, P.R. and S. Silverman, 2002. Using complimentary data: An investigation of student attitude in physical education. J. Sport Pedagogy, 8: 74-91. 
Subramanian, P.R. and S. Silverman, 2007. Middle school students' attitudes toward physical education. Teach. Teacher Educ., 23: 602-611. DOI: 10.1016/J.TATE.2007.02.003

Tannehill, D. and D. Zakrajsek, 1993. Student attitudes toward physical education: A multicultural study. J. Teach. Phys. Educ., 13: 78-84.

Tannehill, D., J. Romar, M. O'Sullivan, K. England and D. Rosenberg, 1994. Attitudes toward physical education: Their impact on how physical educators make sense of their work. J. Teach. Phys. Educ., 13: 406-420.
U.S. Department of Health and Human Services, 2000. Healthy People 2010: Understanding and Improving Health. Department of Health and Human Services.

Xiang, P., R. McBride and J. Guan, 2004. Children's motivation in elementary physical education: A longitudinal study. Res. Quar. Exerc. Sport, 75: 71-78.

Zeng, Z.H., R.W. Leung and M. Hipscher, 2010. An examination of teaching behaviors and learning activities in physical education class settings taught by three different levels of teachers. J. Soc. Sci., 6: 18-28. DOI: $10.3844 /$ jssp.2010.18.28 